UDC 519.216.1

\title{
BEHAVIOR OF FIXED POINT CONGRUENT PERIODIC TRAJECTORIES OF NONLINEAR MAPS IN DYNAMICAL SYSTEMS THEORY
}

\author{
Vostrov G., Khrinenko A., Kolesnichenko V. \\ Odessa National Polytechnic University
}

\begin{abstract}
This paper considers problems that arise during number sequence generation based on nonlinear dynamical systems. Complex systems can depend on many parameters analysis and examination of one-dimensional maps was per-formed since these maps are dynamical systems. Dependence of iterative fixed points for nonlinear maps on the properties of functions and function domain numbers was investigated. Several approaches to randomness evaluation and, accordingly, methods for estimating the degree of randomness of a particular sequence were considered. The properties and internal structure of sequences obtained on the basis of nonlinear maps were also examined in accordance to their influence on the degree of randomness.
\end{abstract}

Keywords: Chaos, pseudorandom sequences, nonlinear maps, prime numbers.

\section{Introduction}

The current state of development of information technology creates the illusion that existing methods of its application give opportunity to humanity to solve any problem of complex dynamical system managment for any level of complexity. This is facilitated by the well-developed idea that problems and solving technologies for them do not largely depend on the level of development of the mathematical foundations of information theory, however in reality the number of blind spots in the theory of application of novel methods only increases, since current discoveries raise more and more new questions. In this regard, the development of the theory of dynamical systems is more relevant than ever [1].

The task of studying the structure of trajectories of cyclic fixed points of nonlinear dynamical systems is assigned to the so-called blind spots. According to Sharkovskii's theorem [2], if a discrete dynamical system on the real line has a periodic point of period 3, then it must have periodic points of every other period. In general, this statement determines that it leads to the creation of so-called chaos.

In the chaotic behavior of dynamical systems, the slightest inaccuracy in determining the initial state of the system increases rapidly over time and, therefore, forecasting becomes ineffective or even impossible. Understanding of chaos becomes one of the most important problems of our time. Solution of this problem leads us to attempts to understand all the variety of nonlinear phenomena and processes in real-world aspects $[3,15]$.

Due to the dynamical nature of chaotic modes and their sensitivity to the slightest oscillations, they

(C) Vostrov G., Khrinenko A., Kolesnichenko V., 2020 provide effective control by external controlled influence. The purpose of such influence can be realization of periodic mode in system instead of chaos or getting to the given phase space. This idea was firstly adopted and examined in papers [4,5] and showed its prospectiveness in both theoretical and applied aspects till now.

Another usage of nonlinear dynamics ideas and methods is related to the problem of signal processing. Let's assume that a distant and inaccessible object is being studied, so the possibilities of research are limited by the analysis of the signal coming from it.

The purpose of this work is to create a mathematical basis for information technology analysis of structures of cyclic trajectories of complex dynamical systems, as a way to determine chaos in nonlinear stochastic dynamical systems of varying complexity. It is especially important to identify the structure of chaotic processes of trajectories of cyclic fixed points over a large length, which are determined by numbers in form $1 / \mathrm{p}$, where $\mathrm{p}$ is a large prime number. The analysis of such trajectories is important for the reason that the structures of trajectories for $\mathrm{n} / \mathrm{m}$ values for fixed points can be analytically represented through the properties of trajectories determined by prime numbers using functional maps formed on the basis of group theory [8]. Entropy can be viewed as a tool to measure trajectory complexity. Computation of difference between entropy before periodic trajectories structural analysis and entropy after trajectories structure examination can be seen as a process of data mining in regard to measure of randomness for given dynamical systems trajectories [9].

In this way, it will be determined whether the obtained trajectories have a deterministic structure and how it affects the structure on the set of integers, 
rational or real numbers. The dynamical properties of cyclic trajectories can be thoroughly investigated only by transformation of mathematical models into a recursive form. The theory of recursive functions allows to make the transition to representation of given models in recursive form [10].

Mathematical theory of iterative maps in the general case refers to the theory of recursive functions, the theory of dynamical systems, the theory of differential equations and is deeply related to modern chaos theory [11]. Dynamical systems use iterations of the form $x_{n} \rightarrow x_{n+1}=f\left(x_{n}\right)$, where the function $f(\mathrm{x})$ is defined on the interval $[0 ; 1]$ and translates into itself and belongs to the class of primitive recursive functions.

An important example of such systems is the process of population development in an environment with certain properties [16]. The mathematical model of the stochastic dynamical system of population development can be presented in Wright-Fisher form:

$$
\begin{aligned}
d x_{\xi}(t)= & c \cdot \sum_{\xi^{\prime} \in S} q_{\xi^{\prime}, \xi}\left(x_{\xi^{\prime}}(t)-x_{\xi}(t)\right) d t+ \\
& +s \cdot x_{\xi}(t)\left(1-x_{\xi}(t)\right) d t+ \\
+ & \sqrt{\gamma x_{\xi}(t)\left(1-x_{\xi}(t)\right)} d \omega_{\xi}(t), \\
& x_{\xi}(0) \in[0,1] \forall \xi \in S
\end{aligned}
$$

This equation is reduced to an iterative form which has the following form.

$$
\begin{gathered}
x_{\xi}(n+1)=x_{\xi}(n)+ \\
+c \cdot \sum_{\xi^{\prime} \in s} q(i, j)\left(x_{\xi^{\prime}}(n)-x_{\xi}(n)\right)+ \\
+s \cdot x_{\xi}(n)\left(1-x_{\xi}(n)\right)+ \\
+\gamma \sqrt{x_{\xi}(n)\left(1-x_{\xi}(n)\right)} \omega(n)
\end{gathered}
$$

The obtained iterative equation has a complex form. The behavior of such a dynamical system largely depends on the values of the constants $c, s, \gamma, S, q(i, j)$, of the environment properties $\mathrm{e}$ $x_{\xi^{\prime}}(t)$, characteristics of the change in the genetic code of the population $\omega_{\xi}(t)$ and the magnitude of its drift.

As a process $\omega_{\xi}(t)$ in Wright-Fisher model Wiener processes are considered, such as Brownian motion or geometric Brownian motion, which is everywhere positive and has a log-normal distribution law. It is proved that in the most general form such a dynamic system is described by a random process which is a martingale. Fundamental study of periodic fixed points and their trajectories of such dynamical systems requires possession of detailed information on the same characteristics of their components.

It should be noted that dynamical systems given by different mathematical maps sometimes allow to obtain the same information. Another class of problems that is related to the development of estimation methods of fractal measure for sets, functions, random processes and the formation of information in systems and control methods for dynamical systems based on information on the structure of their cyclic trajectories.

\section{Structural analysis methods for periodic trajectories of nonlinear dynamical systems}

The results of the study of dynamical systems depend on the properties of parameters that characterize these systems. Systems can depend on many parameters, but the results of analysis and research of dynamical systems based on one-dimensional maps can be applied to a wide range of complex dynamical systems.

Consider the maps of the following classes: «Tent», «Asymmetric tent», «Discontinuous tent», «Sawtooth», "Logistic map", «Square root logistic map», «Sine map», "Algebraic map". This choice of maps is subjected to the fact that some classes of complex maps can be considered as functions of certain combinations of these maps. In addition, there are relationships between these maps that are a source of important information about the relationships between classes of primes used in discrete logarithm theory, in methods for constructing efficient pseudorandom number generators and in number theory $[13,14]$. The abovementioned maps are considered as a function $f(x): R \rightarrow R$.

Then $f^{n}(\mathrm{x})$ denotes the nth iteration of the function $f(\mathrm{x})$. Then $f^{n}(\mathrm{x})$ is $\mathrm{n}$-fold composition of the function $f(\mathrm{x})$ with itself. If $x_{0} \in \mathbb{R}$, then the orbit or trajectory for $x_{0}$ is a sequence $x_{0}, x_{1}=f\left(x_{0}\right), \ldots, x_{n}=f^{n}\left(x_{0}\right), \ldots$.

When dynamical systems are considered, fixed points, cyclic fixed points and their trajectories play an important role. Initial point $x_{0}$ is fixed by condition $f\left(x_{0}\right)=x_{0}$. Based on this, we can conclude that the orbit of a fixed point is a constant sequence $x_{0}, x_{0}, x_{0, \ldots}$. These are such values $x_{0}$ that $f^{n}\left(x_{0}\right)=x_{0}, n>0$, accordingly, like closed orbits, periodic orbits are repeated: $x_{0, \ldots} x_{n-1}, x_{0} \ldots$ Hereinafter, the periodic orbits will be called trajectories. For discrete dynamical systems, several types of fixed points can be distinguished. Suppose that $x_{0}$ is a fixed point for $f$, then $x_{0}$ called an attractor or an attractive fixed point for $f$. If there is a neighbor- 
hood $U$ of a point $x_{0}$ on the set $\mathbb{R}$ with such a property that, if the following conditions are met: $y_{0} \in U$, then $f^{n}\left(y_{0}\right) \in U$ for all $n$ and, moreover, $f^{n}\left(y_{0}\right) \rightarrow x_{0}, n \rightarrow \infty$. Similarly, $x_{0}$ is defined as a repellent or repulsive fixed point if all orbits (except $x_{0}$ ) leave $U$ during iterations of function $f(x)$.

Consider the symmetric «Tent» map $g_{1}(x)$ and the algebraic map $\operatorname{alg}(x)$ that calculates residue modulo prime on the basis of $a$ that is greater than 1 and initial value $x_{0}=1 / p$ that defines behavior of given maps.

$$
\begin{gathered}
g_{1}\left(x_{n}\right)= \begin{cases}2 x_{n}, & x_{n}<1 / 4 \\
1-2 x_{n}, & 1>x_{n} \geq 1 / 4\end{cases} \\
\operatorname{alg}\left(x_{n}\right) \equiv a \cdot x_{n}(\bmod p)
\end{gathered}
$$

It was proved that a number $a$ under this condition is a classifier of the set of all prime numbers. Assuming that $\operatorname{card}_{\mathrm{g}_{1}}(1 / \mathrm{p})$ represents the cyclic trajectory length for a prime number $p$ for map $\mathrm{g}_{1}(x)$ the following statement holds.

Statement 1. For any prime number $p$ value of $\mathrm{p}-1$ is always divisible by $\operatorname{card}_{\mathrm{g}_{1}}(p)$ and its value $(p-1) / \operatorname{card}_{\mathrm{g}_{1}}(p)$ always coincides with $\operatorname{ind}_{a}(p)$ for an algebraic map under the condition that $\mathrm{a}=4$.

The validity of this statement is proved by the method of computer modeling, the general principle of its construction is given in [10,11]. It follows that symmetric tent map can be used to analyze the properties of prime numbers. At the same time, the results of the same computer modeling show that the trajectories of algebraic map and symmetric tent map do not coincide in their structure in case if they are reduced to the same scale of values along the ordinate axis.

Although the map «Sawtooth» $g_{2}(x)$ is considered one of the simplest examples of a nonlinear dynamical system, it demonstrates an important property that is inherent in more complex algebraic maps with $\mathrm{a}=2$ on prime numbers set and initial value $x_{0}=1 / p$.

$$
g_{2}\left(x_{n}\right)=\left\{\begin{array}{l}
2 x_{n}, \quad x_{n}<1 / 2 \\
2 x_{n}-1, \quad 1>x_{n} \geq 1 / 2
\end{array}\right.
$$

Similar to statement 1 , if $\operatorname{card}_{\mathrm{g}_{2}}(p)$ is a trajectory length for map $g_{2}(x)$ and $\mathrm{x}_{0}=1 / \mathrm{p}$, then the following statement is valid.

Statement 2. For any prime number $\mathrm{p}>3$ value of $\mathrm{p}-1$ is always divisible by $\operatorname{card}_{\mathrm{g}_{2}}(p)$ and its value $(p-1) / \operatorname{card}_{\mathrm{g}_{2}}(p)$ coincides with $\operatorname{ind}_{a}(p)$ for algebraic map with condition $a=2$.

The validity of this statement immediately follows from the fact that the value of the numerator of the fraction reflected in each iteration coincides with the value of the corresponding iteration of the algebraic map $g_{2}(x)$. Thus, the map $g_{2}(x)$ can be used to analyze the classification of prime numbers, the construction of generators and complex dynamical system modeling [9].

Consider a map $g_{3}(x)$ that has a point of discontinuity, i.e. it can be considered as discontinuous tent at $x=1 / 2$. At the point of discontinuity $g_{3}(1 / 2)=1 / 2$ in this model, but the discontinuity can take place at another $\mathrm{x}$ values. Initial value for this map is also $x_{0}=1 / p$.

$$
g_{3}\left(x_{n}\right)=\left\{\begin{array}{l}
2 x_{n}, \quad x_{n}<1 / 2 \\
1-x_{n}, 1>x_{n} \geq 1 / 2
\end{array}\right.
$$

It was proved that on a set of numbers $\mathrm{x}_{0}=1 / \mathrm{p}$ given map has cyclic trajectories with length $\operatorname{card}_{g_{3}}(1 / p)$ that in general case does not divide $(\mathrm{p}-1)$ despite the fact that the map can be classified as tent map modification (discontinuous tent). The dynamical properties of this map indicate that the lack of information about the properties of cyclic trajectories can lead to its incorrect use in the approximation of complex dynamical systems. This fact suggests that in dynamical system modeling it is necessary to have accurate information about the properties of the components of mathematical models. This fact is important even in the analysis of fixed points of absolute form. It is supported by tent map behavior at the point $x_{0}=0.666$. In the general case, the map can have a significant number of such fixed points and if their locations have not taken into account the lack of information about such points can lead to error growth during simulation processes. These facts suggest that modeling of such dynamic systems requires accurate information about the properties of all components of the mathematical model.

From this knowledge follows a crucial question: if a fixed point, or periodic point, exists in the considered dynamic system, given $f$, does it occur with small system oscillations? In the context of nonlinear dynamical systems, the following types of oscillations can be distinguished:

- initial state fluctuation: "Are the behavior and development of systems with similar initial states similar?"; 
- fluctuation of the function $f$ : " $f$ is defined only approximately";

- stochastic fluctuations: "In fact, the expression $x_{n}=f\left(x_{n-1}\right)$ looks differently, but micro-noises can be taken into account with the help of an additional factor $x_{n}=f\left(x_{n-1}\right)+r\left(x_{n-1}\right)$, where $r(x)$ is a small random increment, i.e. a small variation of $f\left(x_{n-1}\right)$.

Behavioral study of cyclic trajectories of tent map class fixed points is an equally important task in process of fundamental theory of complex dynamical systems creation. A complete study of the attractors of this class of maps was performed in various researches. However, there is no information about the structure of their trajectories. It is necessary to create methods that would allow under any circumstances to have detailed information about trajectory properties.

Asymmetric tent.

An example of a map that belongs to the tent class is an asymmetric map. It can be considered as an extension of the standard «Tent»:

$$
f\left(x_{n}\right)= \begin{cases}\frac{x_{n}}{a}, & 0 \leq \mathrm{x}_{\mathrm{n}} \leq \mathrm{a} \\ \frac{1-x_{n}}{1-a}, & \mathrm{a} \leq \mathrm{x}_{\mathrm{n}} \leq 1\end{cases}
$$

The chaotic behavior for this map is shown in Fig. 1 that represents partial trajectory of the map with arbitrarily selected prime number. The essence of chaos in this case is that the values periodically approach each other, but never repeat themselves.

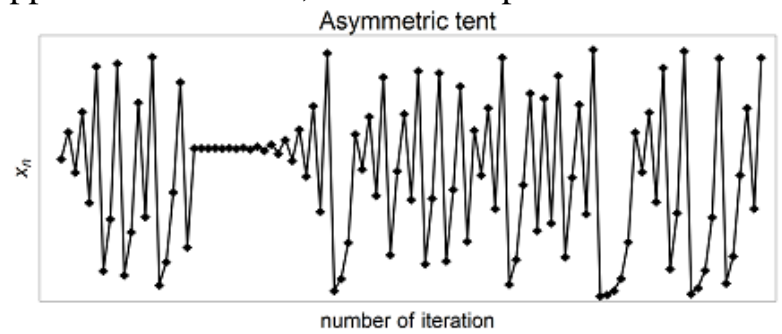

Fig. 1. - Chaotic structure of asymmetric tent

Logistic map.

The logistic map is defined as follows:

$$
f\left(x_{n}\right)=r x_{n}\left(1-x_{n}\right),
$$

where $r \geq 0$ is the parameter that fixes population growth. Logistic map demonstrates the properties of nonlinear dynamical systems that simulate a wide class of dynamical processes that belong to the class of population development. It should be noted that processes occurring at currency and stock markets, actuarial mathematics systems and others can be effectively modeled using logistic map. The choice of this map as a component of the mathematical model is associated with the problem of choosing the value of the parameter $r$. It is proved that if the value of the parameter is less than 3.6, then the logistic map simulates the processes of sustainable development of dynamics and for larger values the behavior of trajectories acquires more chaotic nature. Especially chaotic character of cyclic trajectories is observed when approaching $r=4$. Under such conditions, it becomes extremely important to have information about the behavior of a dynamical system when $\mathrm{x}$ variable takes the value of the form $1 / p$ where $p$ is a prime number of significant values. The properties of trajectories in such cases have not been studied. At least in the literature, such information is absent, although logistic map is the subject to a wide range of studies.

Sine map.

The map $f(x)=\sin (\pi x)$ is very similar in structure to the logistic map, it should be noted that this function usually takes values from the interval $[0,1]$ and this function is associated with a rather complex group that is not fully analyzed. In addition, this function usually takes irrational values, thus in modeling of cyclic trajectories intermediate values of the trajectories will be rounded systematically, which must be taken into account due to the fact that it will lead to the transition to another state of the dynamical system.

Square root logistic map.

This map is a modification of logistic map and can be represented in next form:

$$
f(\mathrm{x})=\sqrt{r x_{n}\left(1-x_{n}\right)}
$$

As a rule, it is used in modeling of slow processes of genetic changes in dynamical systems. This is especially true for stock markets and the processes of genetic code change for developing populations, such as coronaviruses. It should be noted that in such models the constant $a$ takes values much smaller than 3.6 because the processes of genetics slow change of such dynamical systems are modeled. In this case, the strategy of resource use of the environment is systematically adapted to changes in its resources, and therefore the study of cyclic trajectories of such maps is an important task.

\section{Congruence measure for given maps}

Provided one-dimensional maps demonstrate similar behavior of the corresponding nonlinear dynamical systems. All these maps show so-called chaotic behavior since they are sensitive to the initial conditions. As a rule, the given maps are considered on the interval $[0,1]$, taking into account that the obtained results are easily transferred to the intervals 
of any length $[1, n]$, taking into account the significant similarity of their structures except for algebraic map. Algebraic map is included in the work due to the fact that it is fundamental in modern number theory and pseudorandom number generation methods and modern cryptography. Framework of analysis of the congruence of different maps is the proof that between the cyclic fixed points there is an unambiguous correspondence at which the congruent fixed points have the same length. Algebraic map can be seen as a connecting link between function theory and number theory.

Algebraic map can be seen as a tool that is the foundation of the relationship between function theory and number theory. Figure 2 shows combination of logistic, tent and sine map on the interval $(0,1)$. Analysis of these maps leads to the conclusion that their periodic fixed points are different, but the length of their periodic trajectories can be the same value. Such fixed periodic points can then be considered as topologically equivalent or congruent. It is necessary to take into account that the structures of their trajectories will be different. Such properties of cyclic fixed points must be taken into account when analyzing the behavior of dynamical systems that are a function of such maps. Therefore, proving the congruence of such maps is an important part of the development of information technology in the theory of dynamical systems.

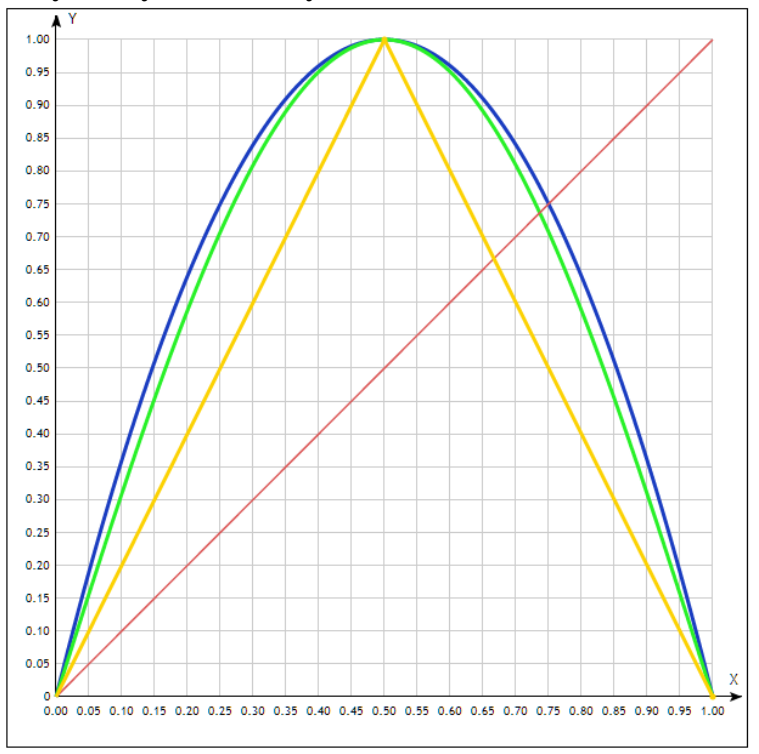

Fig. 2. - Combined representation of 3 maps

Consider "Tent" map:

$$
f_{1}\left(x_{n}\right)=\left\{\begin{aligned}
2 x_{n}, & x_{n}<\frac{1}{4} \\
1-2 x_{n}, & 1>x_{n} \geq \frac{1}{4}
\end{aligned}\right.
$$

Particular attention to map (10) draws the fact that it shares many properties with the logistic map (8) when $r=4$ in the iteration process. This feature indicates their conjugation. Assuming that $I$ and $I$ represent some intervals for maps $f: I \rightarrow I, g: J \rightarrow J$. then it could be assumed that the maps $f$ and $g$ conjugates, if there is a homeomorphism $h: I \rightarrow J$, still $h$ satisfies the equality of conjugation $h \circ f=g \circ h$. Conjugacy compares orbits $f$ to orbits $g$. This follows from the fact that $h\left(f^{n}(x)\right)=g^{n}(h(x))$ for all $x \in I$ such that $h$ compares the $n$-th point of the orbit for $f$ from $x$ to the $n$-th point of the orbit $g$ from $h(x)$.

Statement 3. Tent map is congruent with logistic map, square root logistic map. and sine map.

The proof is based on the following sequence of steps that follow from the work [4]. The validity of the fact that sine map is congruent to the logistic map follows from the following simple transformations. Let's define the equation of conjugation by analogy of definition of logistic map at a $=4$ :

$$
h(2 x)=4 h(x)(1-h(x))
$$

for $x \in\left[0, \frac{1}{2}\right]$. Note that the above satisfies the function of the form

$$
h(x)=\sin ^{2}(c x)
$$

for any $c>0$ by the formula: $\sin (2 \theta)=2 \sin \theta \cos \theta$.

In order $h$ to be a homeomorphism of the interval itself, it must be monotonic on any interval. Closer examination of homeomorphism defined by formula (12) allows to consider $c=\frac{\pi}{2}$. It follows that $h(0)=0, h(1)=1$ and $h$ is increasing throughout the interval $[0,1]$.

To make sure that (12) is really a topological conjugation, it is necessary to examine it on the interval $x \in\left[\frac{1}{2}, 1\right]$ :

$$
h(2(1-x))=4 h(x)(1-h(x))
$$

Let's perform substitution and simplification:

$$
\begin{aligned}
& h(2(1-x))=\sin ^{2}(\pi(1-x))=\sin ^{2}(\pi x)= \\
& =4 \sin ^{2}\left(\frac{\pi x}{2}\right) \cos ^{2}\left(\frac{\pi x}{2}\right)=4 h(x)(1-h(x))
\end{aligned}
$$

That was necessary to prove.

Proved statement shows that sine map can be viewed as an example of a topologically conjugate system with logistic map and tent map. From this theorem follows only the fact that in congruent cyclic fixed points the maps have the same lengths of cyclic trajectories, but their structures can be differ- 
ent to a large extent. The values of these maps belong to different classes of numbers. The values of the cyclic trajectories of tent and logistic maps take rational values; square root logistic map belongs to the class of algebraic numbers and sine function is defined on the set of real numbers which in the general case are transcendental. These facts must be taken into account during modeling of the behavior of such dynamical systems due to the fact that automatic rounding of values can lead to an automatic transition to completely different cyclic trajectories [5].

\section{1-D map structure analysis and randomness measure}

Despite the simplicity of these maps their structure largely depends not only on the properties of the functions used for their construction, but also on the properties of the numbers used as initial conditions and parameters. These maps allow you to divide the set of primes into a system of classes based on the length of the iterative process for given primes. Note that there are many prime numbers for which the length of the period is significantly less than the dimension of the number. The sequence obtained for a given number forms a simple structure. Simple structures are characteristic of Fermat, Mersenne numbers and their various generalizations. At the same time, other prime numbers generate sequences for which the length of the period is proportional to its dimension and, accordingly, can show a greater degree of approximation to randomness, but also have periodic elements as shown in Figures 3-5.

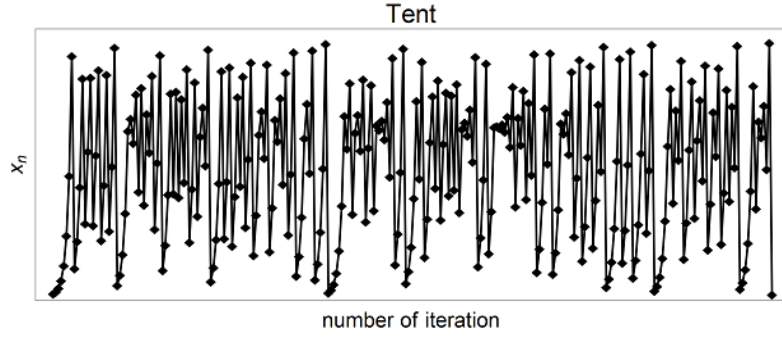

Fig. 3. - Tent map iteration sequence

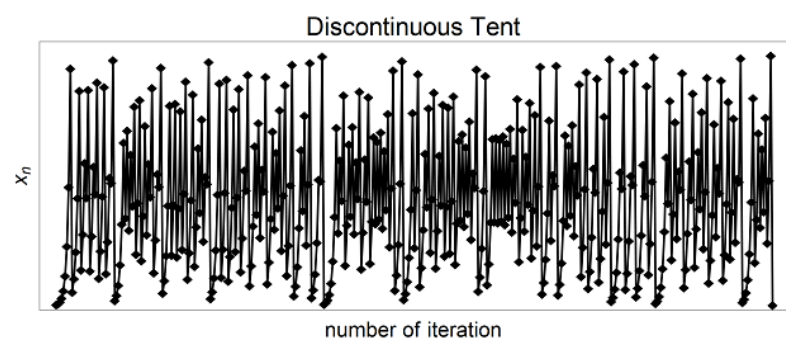

Fig. 4. - Discontinuous Tent map iteration sequence

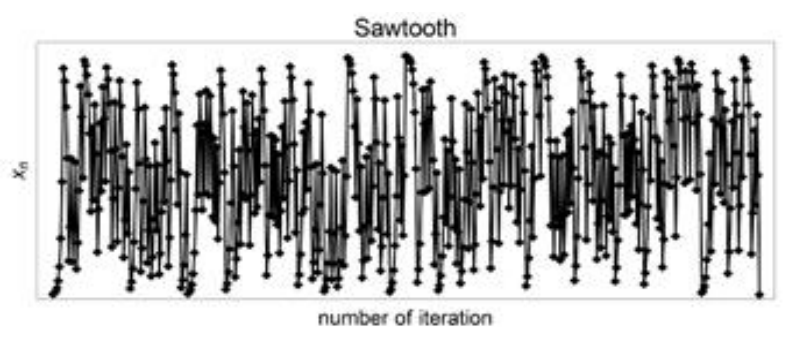

Fig. 5. - Sawtooth map iteration sequence

The structures of given trajectory fragments for the number $1 / p=1 / 649657$ are radically different for these maps. It can be argued that currently analytical methods of their internal structure of periodic fixed points trajectories are not sufficiently developed, but rather simply absent. In dynamical process control systems, mathematical models of which include such maps, implementation of any methods will always be ineffective if we do not take into account internal structure of trajectories of their periodic fixed points. This analysis is especially important provided that the dynamic system belongs to the class of self-organizing, which are now called synergistic dynamic systems. The presence of selforganization processes in such systems does not mean that such systems do not require external control which takes into account behavioral features. Creation of methods of effective management of dynamic systems is possible on condition of the systematic analysis of their behavior. This requires methods of sequential analysis of their trajectories in which fragments of trajectories are distinguished, which have certain properties and at the same time according to which systematic actions of purposeful nature are taken.

Creation of methods for analysis of trajectories structure of periodic fixed points can be associated with another class of problems. In dynamic systems, it is often important to have information according to which laws the system switches from one state to another. Emergence of fractal components may be a sign of self-organization processes in the systematic behavior of a dynamic system.

The question of a certain degree of similarity of internal structures arises. For example, for the prime number 649657, Figure 6 shows the internal structure of iterative processes for maps, where the dotted line shows the resulting sequences and the solid line shows the internal parts within the sequences that give the maximum value of the correlation coefficient. 

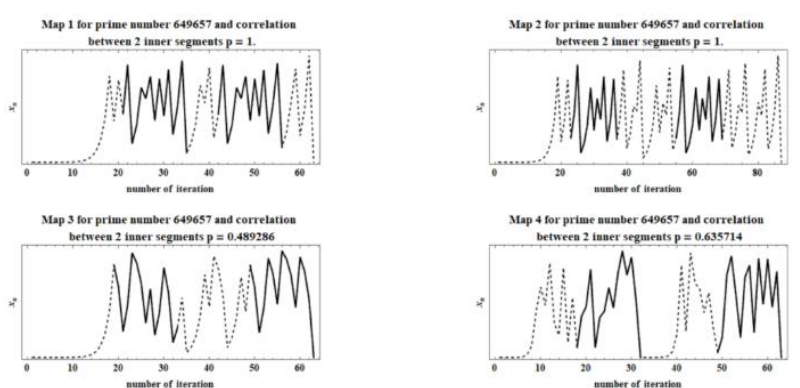

Fig. 6. - Structure of sequence on the basis of prime number 649657

As can be seen in these sequences, which were obtained using the above maps for some subsequences, give similarity values closer to 0 , indicating the influence of fixed points on the internal structure of the sequence.

To examine trajectories structure, in this paper we consider the application of measures of form estimation and DFT measure as an example of the characteristic measure. Among the various correlation coefficients we will use the Spirman correlation, since the Spirman correlation coefficient does not contain any assumptions about the distribution. Sequences will be called similar if the measure takes a value greater than 0.5. The Spirman correlation coefficient can be calculated using the following equation:

$$
r_{s}=1-\frac{6 \sum d_{i}^{2}}{N\left(N^{2}-1\right)},
$$

where $d_{i}$ - the difference between the rank for each pair of data, and the value $N$ - the number of data pairs. The Spearman correlation coefficient calculates the $p$-value in the same way as the linear regression and Pearson correlation, except that the calculation takes place for ranks, not magnitudes. It is worth noting that the price for the best properties of the Spirman correlation is the greater complexity of the calculations, which is $O(n \log n)$, while the Pearson correlation calculation has the complexity of $O(n)$.

As a result of analysis, a hierarchy of internal cycles according to the length of the cycle, as well as the degree of similarity of the found structures was gotten. This hierarchy can be used to further evaluate the sequence. In accordance with a step-bystep approach to the search for similar subsequences, we obtain a set of values that could identify a subsequence that exceeds the initial value.

Considering the results for the individual sequences, the results of the evaluation of the degree of similarity allow us to obtain a hierarchy of similar sequences based on the length of the internal cycles and the level of similarity presented in table 1 . In this table: $\mathrm{s}-$ length of the pattern, 1 - searched simi- larity measure, pat - initial position of used pattern, comp - some compared pattern, SM - obtained similarity measure for two subsequences.

Table 1.

Similar subsequences for algebraic map and a prime

\begin{tabular}{cccccc}
\hline s & l & pat & comp & lag & SM \\
\hline 11 & 0,7 & $\{9,19\}$ & $\{20,30\}$ & 36 & 0,772727 \\
11 & 0,8 & $\{17,27\}$ & $\{28,38\}$ & 33 & 0,836364 \\
11 & 0,9 & $\{40,50\}$ & $\{51,61\}$ & 53 & 0,972727 \\
15 & 0,7 & $\{19,33\}$ & $\{34,48\}$ & 67 & 0,717857 \\
15 & 0,8 & $\{36,50\}$ & $\{51,65\}$ & 49 & 0,817857 \\
15 & 0,9 & $\{13,27\}$ & $\{28,42\}$ & 67 & 0,907143 \\
20 & 0,7 & $\{11,30\}$ & $\{31,50\}$ & 62 & 0,795489 \\
20 & 0,8 & $\{13,32\}$ & $\{33,52\}$ & 62 & 0,842105 \\
25 & 0,7 & $\{50,74\}$ & $\{75,99\}$ & 6 & 0,731538 \\
30 & 0,6 & $\{10,39\}$ & $\{40,69\}$ & 52 & 0,631146 \\
30 & 0,6 & $\{46,75\}$ & $\{76,105\}$ & 1 & 0,63337 \\
\hline
\end{tabular}

Comparing the chosen similarity measures, the best results from the search for similar sequences demonstrate the DFT measure, since it represents the estimation of the subsequence in the form of the sum of harmonic oscillations, respectively, allows for a more precise estimation. Also, the DFT measure has better computational performance by reducing the dimension, which significantly affects the total time of the calculation for sequences that display a proportional to a prime number of length of the period. The time complexity for the DFT using the fast Fourier transform algorithm is $O(n \log n)$.

\section{References}

1. Balasubramanian, V., Ho, S. and Vovk, V., (2014). Conformal Prediction for Reliable Machine Learning: Theory, Adaptations and Applications. Elsevier.

2. Sharkovsky, A., (2013). Attractors of trajectories and their pools [Attraktory trayektoriy i ikh basseyny]. Kyiv: «Scientific book».

3. Strogatz, S., (2018). Nonlinear Dynamics And Chaos: With Applications to Physics, Biology, Chemistry, and Engineering. CRC Press.

4. Rauch, J., (2014). Conjugating the Tent and Logistic Maps. Available at:

$<$ http://www.math.lsa.umich.edu/ rauch/558/logistic conjugation.pdf> [Accessed 23 September 2020].

5. Hirsch, M., Smale, S. and Devaney, R., (2012). Differential equations, dynamical systems, and an introduction to chaos. Amsterdam: Academic Press. 6. Vostrov, G. and Opiata, R., (2017). Effective computability of the structure of the dynamic processes of the formation of primes. ELTECS, no. 25(101), pp. 432-438. 
7. Uspenskiy, V., (2009). Four algorithmic faces of randomness [Chetyre algoritmicheskikh litsa sluchaynosti]. Moscow: MCNMO.

8. Wang, X., Mueen, A., Ding, H., Trajcevski, G., Scheuermann, P. and Keogh, E. (2012). Experimental comparison of representation methods and distance measures for time series data. Data Mining and Knowledge Discovery, no. 26(2), pp. 275-309.

9. Berndt, D. and Clifford, J., (1994). Using Dynamic Time Warping to Find Patterns in Time Series. In: AAAIWS, Knowledge Discovery and Data Mining, Proceedings of the 3rd International Conference, July 1994. pp. 359-370.

10. Vostrov, G. and Khrinenko, A., (2018). Pseudorandom processes of the number sequence generation. ELTECS, no. 28(103), pp. 234-241.

11. Vostrov, G. and Khrinenko, A., (2018). Mathematical foundation of information technologies in modern nonlinear dynamical systems. ELTECS, no. 29(105), pp. 163-170.
12. Kholodnyuk, M., Klich, A., Kubichek, M., Marek, M., (1991). Methods for analyzing nonlinear dynamic models. Moscow: Mir.

13. Batchko, R., (2014). A Prime Fractal and Global Quasi-Self-Similar Structure in the Distribution of Prime-Indexed Primes. arXiv. Available at: <https://arxiv.org/abs/1405.2900> [Accessed 25 September 2020].

14. Vartziotis, D. and Wipper, J., (2016). The fractal nature of an approximate prime counting function. arXiv. Available at:

$<$ https://arxiv.org/abs/1611.01949 (2016)> [Accessed 25 September 2020].

15. Skiadas, C. and Skiadas, C., (2016). Handbook of Applications of Chaos Theory. CRC Press.

16. Dawson, D., (2018). Multilevel mutationselection systems and set-valued duals. Journal of Mathematical Biology, no. 76, pp. 295-378.

\title{
ПОВЕДІНКА КОНГРУЕНТНИХ ЦИКЛІЧНИХ ТРАЕКТОРІЙ НЕРУХОМИХ ТОЧОК НЕЛІНІЙНИХ ВІДОБРАЖЕНЬ В ТЕОРІЇ ДИНАМІЧНИХ СИСТЕМ
}

\author{
Г. М. Востров , А. О. Хріненко , В. Ю. Колесніченко \\ Одеський національний політехнічний університет
}

\begin{abstract}
Анотація. В даній роботі розглядаються аспекти формування числових послідовностей на основі нелінійних динамічних систем. Складні системи залежсні від властивостей багатьох параметрів, тому аналіз та детальний розгляд одновимірних відображень був здійснений у даній роботі, оскільки дані відображення представляють собою приклад простих динамічних систем. Вплив ичклічних нерухомих точок також був предметом дослідження в роботі. Було розглянуто структуру траєкторій наведених відображень, а також представлено початкові спроби їхнього представлення та аналізу. Показано, що властивості простих чисел, за допомогою яких формуються псевдовипадкові послідовності, впливають на наявність у внутрішній структурі отриманих послідовностей фрагментів, щз істотно погіршують міру випадковості та роблять послідовність непридатною до використання в тих задачах, де вимагається непрогнозованність елементів числової послідовності. Таким чином,висувається вимога щодо ступеня подібності будьяких обраних підпослідовностей при генераиії псевдовипадкових послідовностей. Аналізуючи послідовності з точки зору непрогнозованості, розглядається можливість отримання елементів послідовності на основі інформації про попередні елементи иієї послідовності. Відповідно, наявність періодичних подібних підпослідовностей порушує умову непрогнозованості і не дозволяє розглядати таку послідовність як псевдовипадкову. Результати отримані в ході роботи дозволяють оцінити кожне з використаних відображень та зробити висновок, що для отримання надійних псевдовипадкових послідовностей необхідно будувати методи, що дозволять отримувати найменшу кількість внутрішніх подібних підпослідовностей $і$, відповідно, найменшою мірою ӥхньої подібності.

Ключові слова: Хаос, псевдовипадкові послідовності, нелінійні відображення, прості числа.
\end{abstract}




\title{
ПОВЕДЕНИЕ КОНГРУЭНТНЫХ ЦИКЛИЧЕСКИХ ТРАЕКТОРИЙ НЕПОДВИЖНЫХ ТОЧЕК НЕЛИНЕЙНЫХ ОТОБРАЖЕНИЙ В ТЕОРИИ ДИНАМИЧЕСКИХ СИСТЕМ
}

\author{
Г. Н. Востров , А. О. Хриненко , В. Ю. Колесниченко \\ Одесский национальный политехнический университет
}

\begin{abstract}
Аннотация. $B$ данной работе рассматриваются аспекты формирования числовых последовательностей на основе нелинейных динамических систем. Сложные системы зависят от свойств многих параметров, следовательно анализ и детальное рассмотрение одномерных отображений был осуществлен в данной работе, так как данные отображения представляют собой динамические системы. Влияние изилических неподвижных точек также было предметом исследования в работе. Были рассмотрены структуры траекторий приведенных отражений, а также представлены начальные попытки их представления и анализа.
\end{abstract}

Ключевые слова: Хаос, псевдослучайные последовательности, нелинейные отображения, простые числа.

Received 19.11.2020

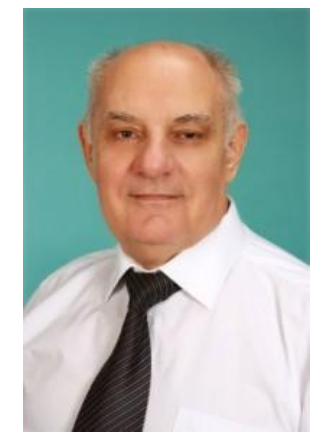

George Vostrov, Ph. D. of Technical Sciences, Associate Professor of the Department of Applied Mathematics and Information Technologies, Odessa National Polytechnic University. Shevchenko ave., 1, Odessa, Ukraine.

E-mail: vostrov@gmail.com, tel. +380503168776

Востров Георгій Миколайович, кандидат технічних наук, доцент кафедри прикладної математики та інформаційних технологій Одеського національного політехнічного університету. Проспект Шевченко, 1, Одеса, Україна.

E-mail: vostrov@gmail.com, тел. +380503168776

ORCID ID: 0000-0003-3856-5392

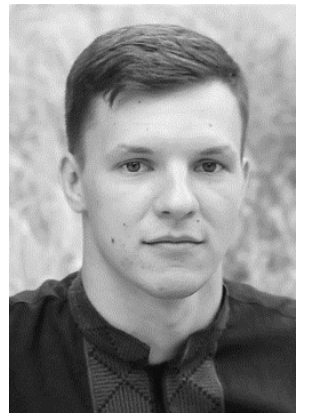

Andrii Khrinenko, Ph.D. student of the Department of Applied Mathematics and Information Technologies, Odessa National Polytechnic University. Shevchenko ave., 1, Odessa, Ukraine.

E-mail: khrinenko@ stud.opu.ua, tel. +380637515228

Хріненко Андрій Олегович, магістр кафедри прикладної математики та інформаційних технологій Одеського національного політехнічного університету. Проспект Шевченко, 1, Одеса, Україна. E-mail: khrinenko@stud.opu.ua, тел.+380637515228

ORCID ID: 0000-0001-6000-2102

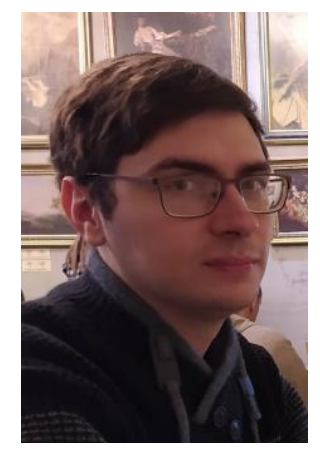

Vladimir Kolesnichenko, student of the Department of Applied Mathematics and Information Technologies, Odessa National Polytechnic University. Shevchenko ave., 1, Odessa, Ukraine.

E-mail: kolesnichenko@gmail.com, tel. +380635552741

Колесніченко Володимир Юрійович, студент кафедри прикладної математики та інформаційних технологій Одеського національного політехнічного університету. Проспект Шевченко, 1, Одеса, Україна. E-mail: kolesnichenko@gmail.com, tel. +380635552741

ORCID ID: 0000-0002-4634-5018 